\title{
Neolithic developments in the Gorgan Plain, south-east of the Caspian Sea
}

Kourosh Roustaei ${ }^{1 * *} \&$ Jebrael Nokandeh ${ }^{2}$

Until about two decades ago, the Neolithic of north-east Iran was known only from a few brief excavation reports: the sites of Yarim Tappeh (Stronach 1972) and Turang Tappeh (Deshayes 1967) on the Gorgan Plain, and preliminary reports of large-scale excavations at the twin mound of Sang-e Chakhmaq in the southern foothills of the eastern Alborz Mountains (e.g. Masuda 1984). In the absence of absolute chronologies, these sites were dated by ceramic assemblages to the sixth millennium BC, and were considered to relate to the so-called 'Jeitun Culture' of southern Turkmenistan (Figure 1; Roustaei 2016a).

Since the 1990s, an increasing number of Neolithic sites have been identified in the north-east region, mainly on the Shahroud and Gorgan Plains, to the south and north of the Alborz Mountains respectively. As a result of excavations at three sites in particularDeh Kheir (Rezvani \& Roustaei 2016), Kalateh Khan (Roustaei 2016b) and Sang-e Chakhmaq (Roustaei et al. 2015)—the evidence from the Shahroud Plain has had greater influence than that from the Gorgan Plain on the characterisation of the Neolithic of this region.

The Gorgan Plain lies to the south-east of the Caspian Sea. This fertile plain enjoys a good amount of precipitation ( $>600 \mathrm{~mm}$ per annum) and is watered by numerous streams originating from the southern and eastern highlands. After the unproductive investigations in the 1960s and 1970s, the first evidence of Neolithic occupation on the Gorgan Plain was discovered during an archaeological survey in 1998 (Nokandeh \& Omrani Rekavandi 1998). Two years later, the first excavation of a Neolithic site in the north-east region since the 1979 Iranian Revolution was conducted by S. Malek Shahmirzadi at the site of Aq Tappeh, about $15 \mathrm{~km}$ east of the town of Gonbad-e Kavous (Malek Shahmirzadi \& Nokandeh 2000).

The ceramic assemblage from Aq Tappeh provided for the first time a basis for identifying the Neolithic material from other sites on the Gorgan Plain. In 2009 a reappraisal programme was launched and directed by one of the current authors (J.N.) on the ceramic collections of around 850 sites of various periods identified through previous surveys and occasional visits. Surprisingly, the results indicated that 57 of these sites can be dated to the Neolithic on the basis of ceramics comparable with those from Aq Tappeh (Abbasi 2011: map 5).

1 Iranian Center for Archaeological Research, Siy-e Tir Street, Imam Khomeini Avenue, 1136917111 Tehran, Iran

2 National Museum of Iran, Siy-e Tir Street, Imam Khomeini Avenue, 1136917111 Tehran, Iran (Email: j.nokandeh@richt.ir)

* Author for correspondence (Email: k.roustaei@richt.ir)

(C) Antiquity Publications Ltd, 2017 ANTIQUITY 91 358, e3 (2017): 1-6

doi:10.15184/aqy.2017.124 


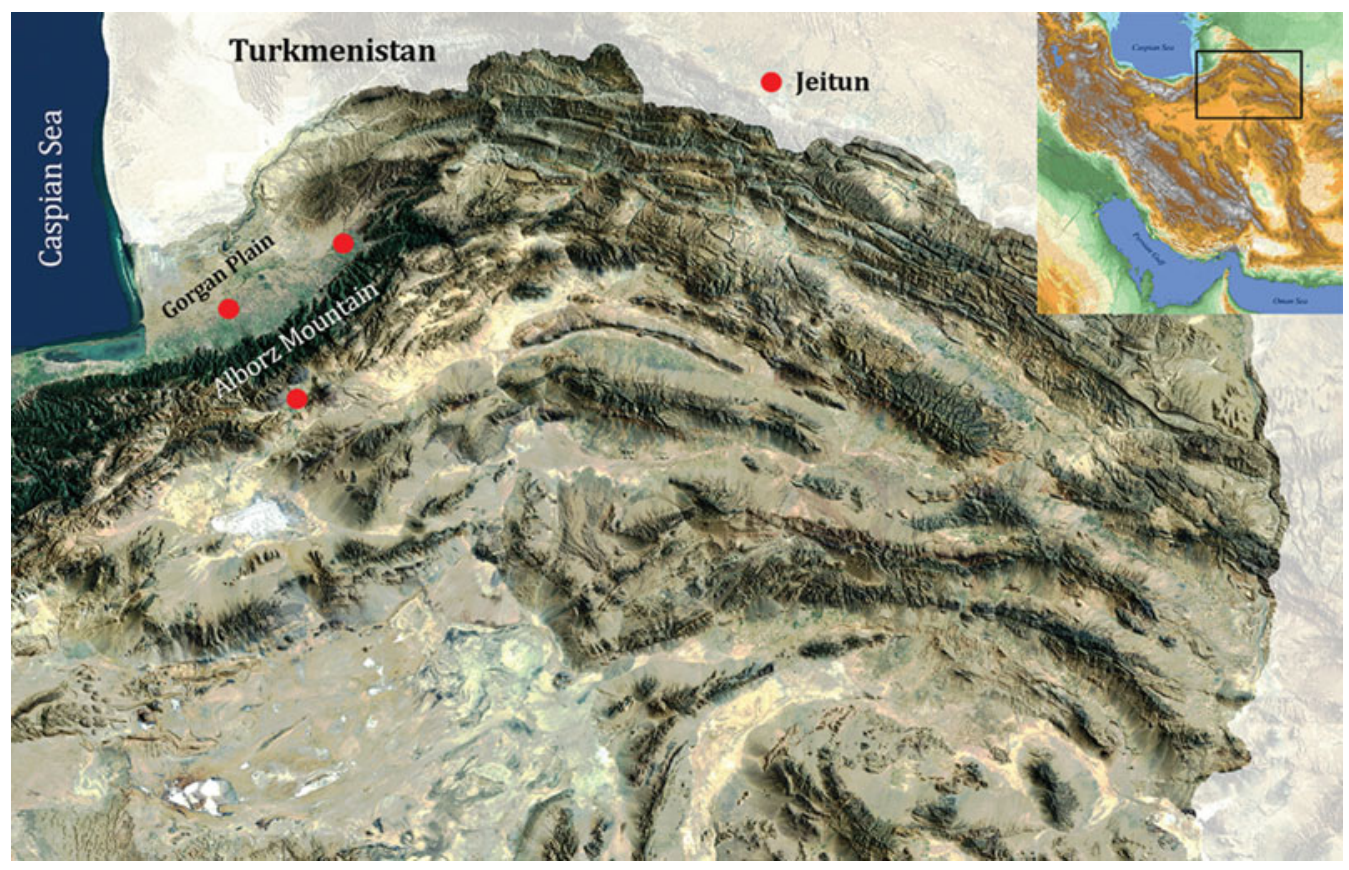

Figure 1. Map of the north-east region of the Iranian Plateau showing the location of three Neolithic sites excavated before 1979 (map generated by M.R. Rokni).

A second development in the study of the Neolithic of the north-east region was a series of excavations on the Shahroud Plain, opposite the Gorgan Plain to the south of the Alborz Mountains (Roustaei 2016a). Excavations at three Neolithic sites (Deh Kheir, Kalateh Khan and Sang-e Chakhmaq) between 2005 and 2009 have provided a wealth of information by which various aspects of the Neolithic culture of the wider region can be defined (Roustaei 2014).

The challenges of integrating two sets of evidence-from the Gorgan Plain, based primarily on the collections from archaeological surveys, and the Shahroud Plain, obtained through stratigraphic excavations enhanced with interdisciplinary and laboratory analysesin order to achieve a more detailed understanding of the Neolithic period of the north-east region has prompted the current authors to launch a new project. This aims to verify the attribution of the newly identified Neolithic sites of the Gorgan Plain on the basis of the absolutely dated ceramic assemblages from the sites of the Shahroud Plain.

The first step of the Gorgan Neolithic Project has involved visiting the sites with suggested Neolithic activity. During two short seasons in March 2015 and March 2016 (each of two weeks), we visited all of the sites that had been previously identified as Neolithic by our colleagues. In the course of these visits, additional information was recorded, including accurate geographic coordinates, the nature and extent of the sites, surface collection and preliminary environmental observations. After visiting the sites and examining the newly collected surface ceramics, 45 sites proved to be Neolithic, while 12 others produced no certain Neolithic ceramic evidence (Figure 2). Instead, we were able (C) Antiquity Publications Ltd, 2017 


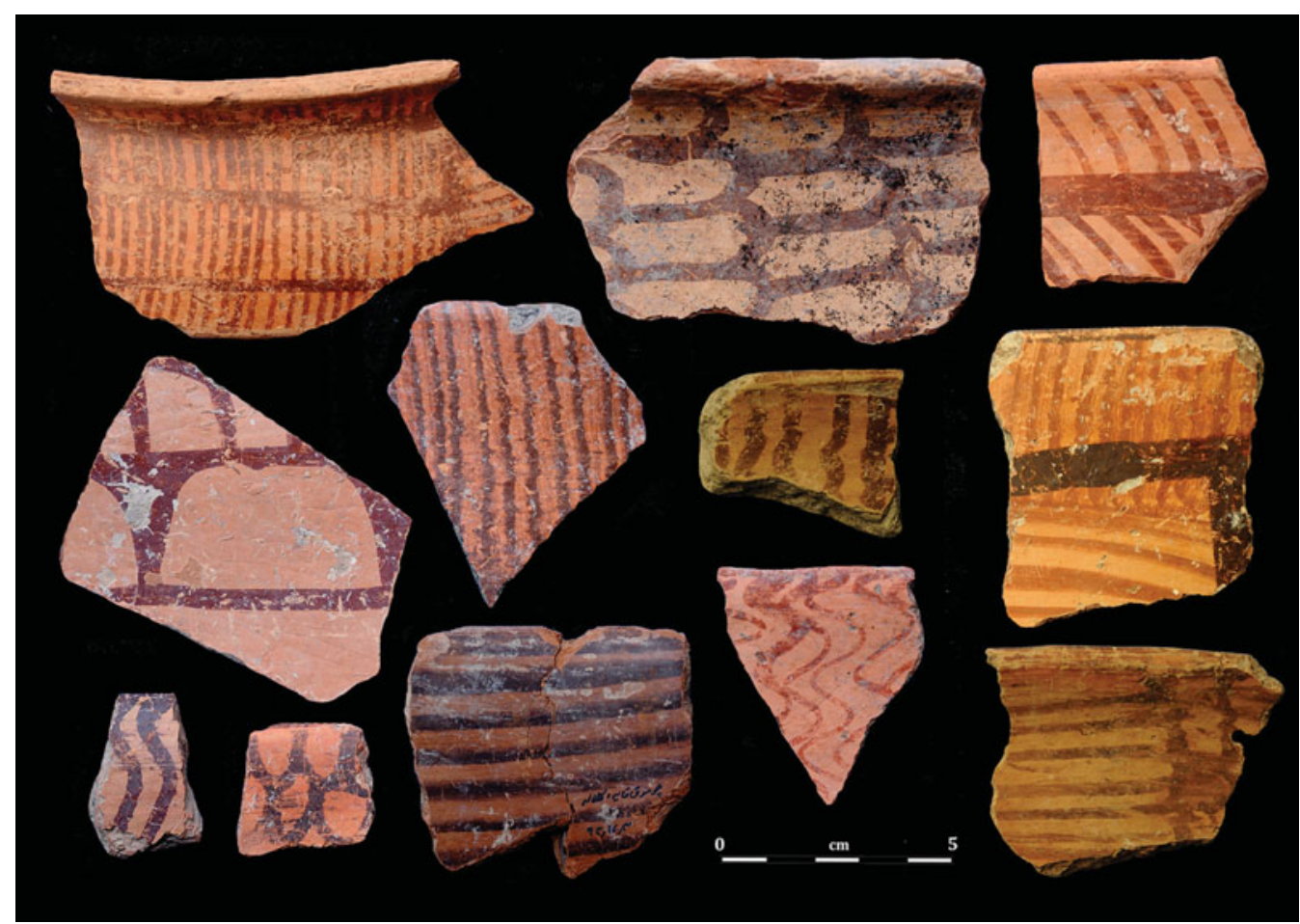

Figure 2. A selection of typical Neolithic ceramics from various sites of the Gorgan Plain.

to identify 10 new sites that were visited but not reported by our colleagues in the local Cultural Heritage offices.

The total number of confirmed Neolithic sites on the Gorgan Plain therefore rises to 55. The majority of these are located on the plain itself, but there are some in the valleys to the south and east (Figure 3). Almost all of the sites are mounded and most are multi-period (Figure 4), complicating assessment of their size during the Neolithic. The few single-period sites are, however, less than 2 ha in extent (Figure 5).

In a wider context, the newly recognised Neolithic sites of the Gorgan Plain contribute to a better understanding of the expansion of Neolithic ways of life from the core areas in the Fertile Crescent (cf. Zeder 2011). Assuming an eastward expansion from the eastern wing of the Fertile Crescent-that is, the Zagros Mountains-into the inner parts of the Iranian Plateau and farther east, the newly identified Neolithic sites of the Gorgan Plain provide a potentially significant source of information. This becomes even more important when we note that the earliest known settlement of the Neolithic in the north-east region, the Sang-e Chakhmaq West Mound (late eighth to early seventh millennium BC) (Roustaei et al. 2015), is almost $700 \mathrm{~km}$ from the next contemporaneous site in the Zagros Mountains (Roustaei 2014). This suggests that earlier but as yet undiscovered sites might be expected on the vast Iranian Central Plateau between the Zagros Mountains and the north-east region.

(C) Antiquity Publications Ltd, 2017 


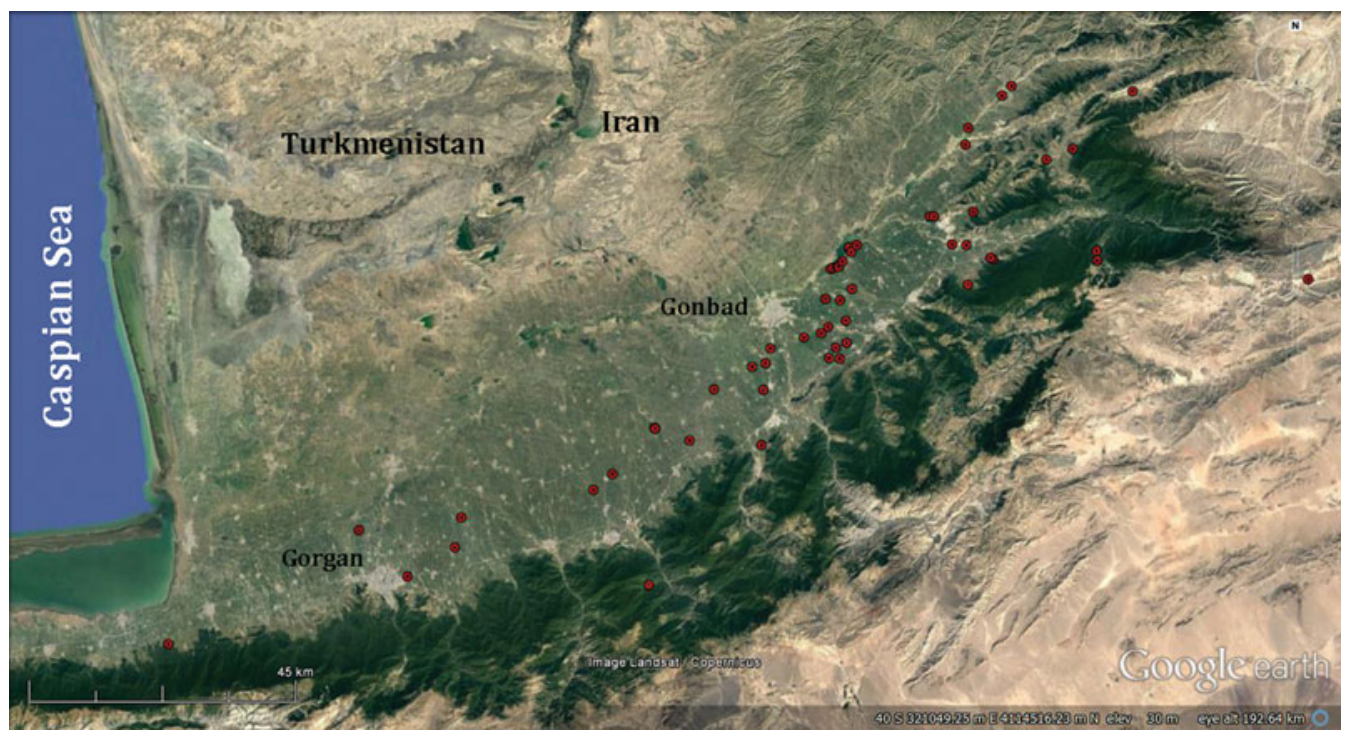

Figure 3. Map of the Gorgan Plain showing the location and distribution of the newly recognised Neolithic sites (by permission of Google Earth).

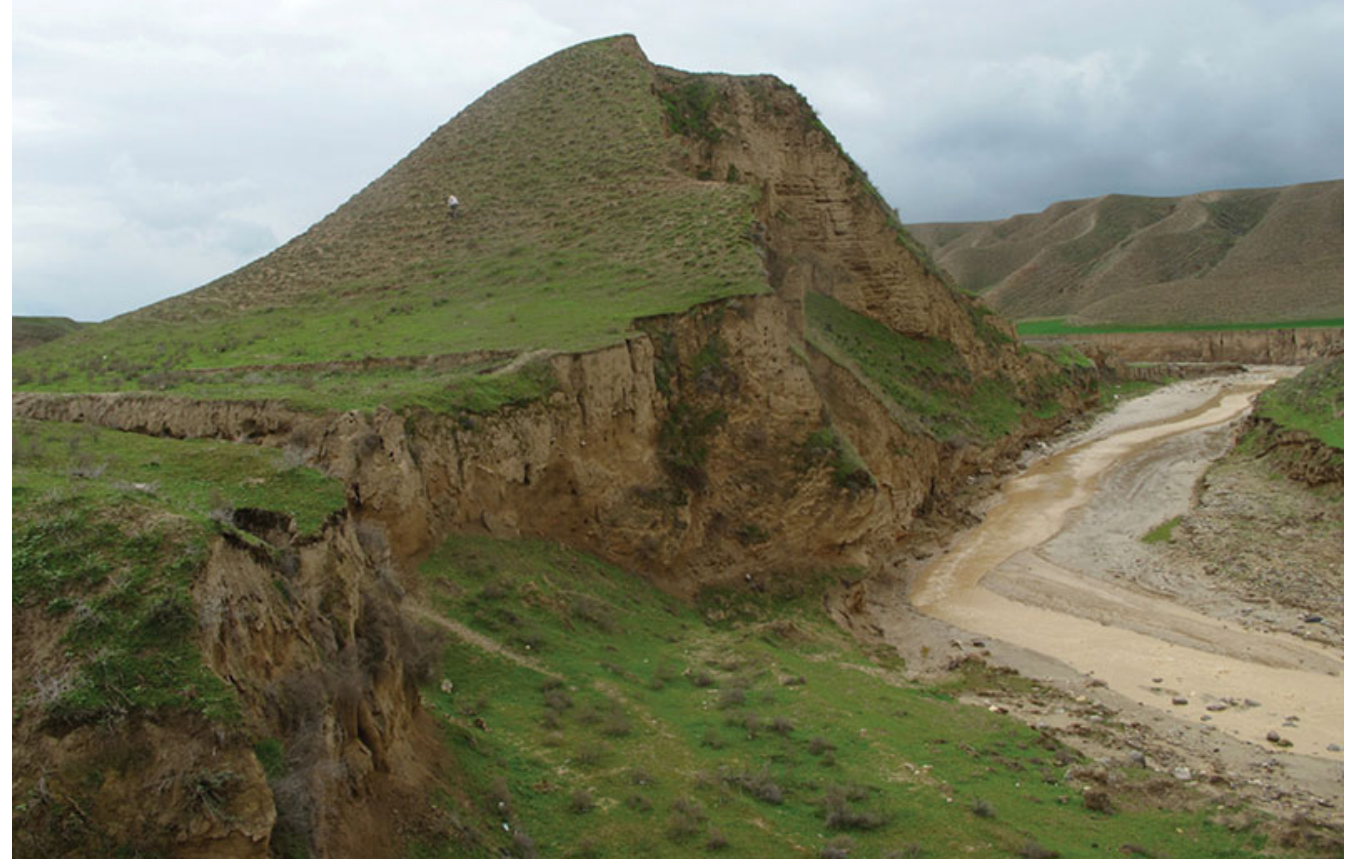

Figure 4. A typical, multi-period mounded site, partly washed away by the Sarisou River.

(C) Antiquity Publications Ltd, 2017 


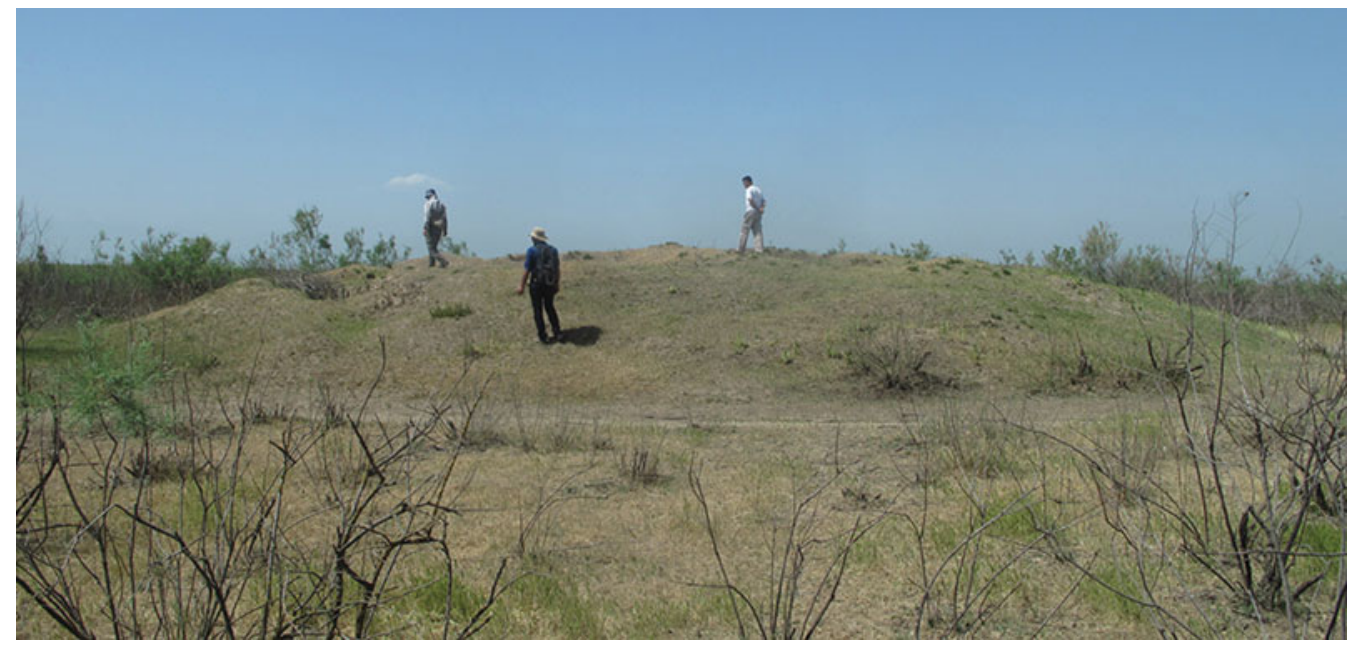

Figure 5. An example of a single-period mounded site.

As discussed in detail elsewhere (e.g. Roustaei 2014, 2016a; Roustaei et al. 2015), the emerging picture of the Neolithic of north-east Iran can also contribute to a better understanding of the Neolithic of southern Turkmenistan: the 'Jeitun Culture'. Finally, as well as links with the regions to the west and north, this almost unparalleled concentration of late seventh- to sixth-millennium BC sites on a comparatively small plain to the east of the Zagros Mountains (although see Sumner 1990: tab. 2) has important implications for varied environmental, subsistence, demographic and social aspects of our reconstruction of the Neolithic societies of Iran.

\section{Acknowledgements}

We would like to thank our colleagues in the Cultural Heritage Office of Gorgan and Gonbad who contributed to various parts of the project, especially H. Omrani Rekavandi, E. Safari, B. Arteghi, Z. Asghari, M. Mahmoudi, M. Rahmani, M. Mousavi, H. Rezaei and A. Amirinezhad.

\section{References}

Aвваsi, G.A. 2011. The final report of excavations at Narges Tappeh, Gorgan Plain. Tehran: Ganjineh Naghsh-e Jahan (in Persian).

Deshayes, J. 1967. Céramiques peintes de Tureng Tépé. Iran 5: 123-31.

Malek Shahmirzadi, S. \& J. Nokandeh. 2000. Aq Tappeh. Tehran: Iranian Cultural Heritage Organization (in Persian).

Masuda, S. 1984. Excavation at Tappeh Sang-e Chaxmaq. Archive für Orientfurschung 31: 209-12.

Nokandeh, J. \& H. Omrani Rekavandi. 1998. Archaeological survey of Jangal-e Golestan. Report prepared for the Iranian Center for Archaeological Research, Tehran (in Persian).
Rezvani, H. \& K. Roustaei. 2016. Preliminary report on two seasons of excavations at Tappeh Deh Kheir, Bastam Plain, north-east Iran, in K. Roustaei \& M. Mashkour (ed.) The Neolithic of the Iranian Plateau: recent research: 15-52. Berlin: ex oriente.

Roustaei, K. 2014. The neolithisation of the northeastern Iranian Plateau. Unpublished PhD dissertation, Tarbiat Modares University (in Persian).

Roustaei, K. 2016a. An emerging picture of the Neolithic of northeast Iran. Iranica Antiqua 51: 21-55.

- 2016b. Kalāteh Khān: a sixth-millennium BC site in the Shāhroud Plain, north-east Iran, in K. Roustaei \& M. Mashkour (ed.) The Neolithic of the Iranian Plateau: recent research: 53-84. Berlin: ex oriente. 
Roustaei, K., M. Mashkour \& M. Tengberg. 2015.

Tappeh Sang-e Chakhmaq and the beginning of the Neolithic in north-east Iran. Antiquity 89: 573-95. https://doi.org/10.15184/aqy.2015.26

Stronach, D. 1972. Yarim Tappeh, in P.R.S. Moorey (ed.) Excavations in Iran: the British contributions: 21-23. Oxford: Organizing Committee of the Sixth International Congress of Iranian Art and Archaeology.
SuMNER, W.M. 1990. Full-coverage regional archaeological survey in the Near East: an example from Iran, in S.K. Fish \& S.A. Kowalewski (ed.) The archaeology of regions: a case for full-coverage survey: 87-115. Washington, D.C.: Smithsonian Institution.

ZEDER, M.A. 2011. The origins of agriculture in the Near East. Current Anthropology 52(S4): S221-35. https://doi.org/10.1086/659307 